\title{
Mulheres de Ferro: Relato de Prática Utilizando Arduíno com Alunas do Ensino Médio em uma Escola Pública
}

\author{
Camila N. Soares, Leticia L. Leite, Aletéia Patrícia. F. de Araujo, Maristela \\ Holanda
}

Departamento de Ciência da Computação - Universidade de Brasília (UnB)

Campus Darcy Ribeiro - CEP 70910-900 - Brasília - DF - Brasil

\{mihcns\} @gmail.com

\{llleite, aleteia, mholanda\}@unb.br

\begin{abstract}
This paper describes an experience conducted with first year high school girls, in a public school at Distrito Federal, with the objective of encouraging students to study in the computer field. To arouse the interest of the students, an arduino workshop was developed - a prototyping platform.
\end{abstract}

Resumo. Este artigo descreve uma experiência realizada com alunas do primeiro ano do ensino médio de uma escola pública do Distrito Federal, com o objetivo de incentivar a atuação delas na área da computação. Para despertar o interesse das alunas foram desenvolvidas, durante o semestre de 2017/2, oficinas de Arduíno.

\section{Introdução}

A disparidade de gênero ainda é um grande obstáculo para as mulheres nas áreas da ciência, sobretudo das exatas. Conforme Maciel e Bim (2010), a redução do número de mulheres nas áreas de Engenharia e de Computação é uma preocupação mundial. Segundo o relatório divulgado pela Sociedade Brasileira de Computação (SBC, 2018), referente ao ano de 2016, é possível observar que apenas 13,65\% dos ingressantes em cursos de Computação são mulheres. Além disso, do total de alunos que concluíram os cursos, apenas $15,48 \%$ são do sexo feminino.

Pesquisas sobre a participação das mulheres nas engenharias revelaram que as discriminações ainda ocorrem apesar das conquistas que elas fizeram também na área tecnológica. Investigações realizadas por pesquisadores e pesquisadoras do Grupo de Estudos e Pesquisas sobre Relações de Gênero e Tecnologia - GeTec, da UTFPR, mostraram sob várias facetas como ocorre esta discriminação. Por exemplo, entre os estudantes das Engenharias há um estranhamento por parte de professores e de alunos pela presença de jovens do sexo feminino nestes cursos. Há depoimentos de alunas afirmando que seus próprios pais, em alguns casos, tentaram impedí-las de cursar Engenharia por ser este um curso mais direcionado ao sexo masculino.

Tendo em vista esta realidade e buscando a inserção de um número maior de mulheres na área de exatas, este artigo apresenta o relato de uma prática realizada em um colégio público que teve como público-alvo estudantes do $1^{\circ}$ ano 
do Ensino Médio. O artigo está organizado, além desta seção, em mais três seções. A Seção 2 apresenta o detalhamento da oficina realizada. A Seção 3 apresenta a conclusão e os trabalhos futuros vislumbrados a partir desta prática.

\section{Organização da Oficina}

A realização da oficina contou com a parceria de uma escola da rede pública de ensino do Distrito Federal que, devido à necessidade de oferta do turno integral, passou a oferecer atividades em turno inverso aos seus estudantes. Diante da necessidade apresentada pela escola e do proposto na disciplina Teoria e Prática Pedagógica em Informática 1 (TPPI1), do curso de Licenciatura em Computação, da Universidade de Brasília (UnB), duas alunas criaram uma proposta de oficina de Arduíno. A oficina se desenvolveu durante um dia da semana, no turno da tarde, durante sete encontros no segundo semestre de 2017. O público-alvo foi definido pela direção da escola como estudantes de $1^{\circ}$ ano do Ensino Médio e, para tanto, as quatro turmas deste nível foram agrupadas em dois grupos para a realização das oficinas. Cada encontro teve duração de uma hora e meia e contou com a participação de 17 estudantes do sexo feminino.

Como o público-alvo não possuía contato com a plataforma Arduíno, a maioria das estudantes não demonstraram interesse na oficina, por isso foi necessário criar uma "propaganda" para o curso. Aproveitando de um momento em que os filmes de super-heróis estão sendo bastante difundidos entre os adolescentes e que o Arduíno pode ser usado em protótipos de robôs, foi utilizada a metáfora do "Homem de Ferro" como base para a divulgação. Tendo em vista que a oficina era voltada para as meninas, verificou-se que a empresa criadora do referido personagem lançou uma versão feminina deste, sendo então criada a oficina "Mulheres de Ferro". Após a divulgação, observou-se que, não só as meninas se interessaram pela proposta, como os meninos também tiveram grande interesse, então foram criadas duas turmas, sendo uma exclusiva para meninas, e outra com meninos e meninas.

\subsection{As Oficinas na Prática}

A equipe da oficina contou com a presença de duas professoras, estudantes de graduação em Licenciatura da Computação, sob o permanente suporte e orientação da professora da disciplina de TPPI1 e da coordenadora da Escola. Assim que as aulas tiveram início observou-se que não era suficiente apenas chamar as estudantes para a oficina, era preciso que elas se interessassem e permanecessem na atividade. Por isso, definiu-se que abordar atividades práticas poderia ter um apelo maior e, esta foi a orientação seguida para o planejamento de cada uma das aulas. $\mathrm{Na}$ realização destas práticas foi utilizado o laboratório de informática da Escola e de kits de Arduíno fornecidos pelo Projeto de Extensão da UnB.

No primeiro encontro foi aplicado um questionário com o objetivo de identificar características dos estudantes que subsidiassem a definição das práticas pedagógicas. Os dados coletados referem-se a: acesso a computador, acesso à Internet e expectativas em relação à oficina. Neste dia também foi reservado tempo para a reflexão sobre os motivos pelos quais as meninas têm menos interesse do 
que os meninos pela área de ciências exatas. Diante desta temática, a maioria das estudantes afirmou que a dificuldade com as disciplinas de exatas refletem na baixa procura pela área por parte do público feminino, e até a falta de incentivo por parte dos professores e pais. Já quando questionados os estudantes afirmaram terem mais interesse na área de exatas pelo uso constante de computadores e videogames.

Ao serem questionadas sobre os motivos para a escolha desta oficina, grande parte das alunas informou que foi devido à curiosidade, para aprender "coisas novas" e, uma estudante respondeu que gostaria de ter o interesse pelas áreas de exatas "despertado". Já os estudantes informaram que a escolha da oficina foi devido à vontade de saber um pouco mais sobre programação.

Dentre as práticas propostas em aula, destaca-se a realização de uma gincana, pois esta proporcionou um momento de aprendizagem ativa, colaborativa e que foi bastante apreciada pelas estudantes. A dinâmica proposta foi a seguinte: foram elaboradas cinco atividades de Arduíno, contemplando o nível mais básico até a utilização de componentes ainda não apresentados aos alunos. A classe foi dividida em grupos, onde cada um deles recebeu um envelope contendo a descrição da atividade proposta. Neste envelope constava uma dica sobre a montagem do circuito e uma sobre o código a ser implementado, este recortado em pedaços de papel (como se fosse um quebra-cabeças).

Os discentes tiveram que montar o código na ordem correta, de acordo com o que foi solicitado na descrição da atividade e mostrar o circuito funcionando corretamente. Concluída esta etapa, o grupo ganhava um novo envelope contendo uma nova atividade, seguindo os mesmos moldes da etapa anterior. Cada envelope permitia aos alunos fazer três perguntas ao professor, cujas respostas seriam apenas SIM ou NÃO, cumprindo desta forma com um dos objetivos propostos, que é o desenvolvimento do pensamento lógico, pois ao pedir ajuda o estudante tem que refletir sobre o que ele realmente quer saber e como deve perguntar. O grupo vencedor da gincana foi o que que terminou todas as atividades corretamente em menos tempo e como prêmio recebeu uma caixa de chocolate.

Apesar da atividade envolver os discentes, houveram alguns contratempos. O principal deles refere-se a uma atividade anual da Escola, a Expressa Arte, pois algumas estudantes faltaram à oficina para praticar dança, $\mathrm{O}$ engajamento das estudantes nas atividades foi significativo, entretanto o comentário de uma participante demonstrou o ambiente em que algumas delas vivem: ao mostrar uma foto do seu trabalho ao pai, recebeu o seguinte comentário: "Você não é tão burra quanto parecia.". Neste momento, as professoras da oficina discutiram a questão com a aluna, visando incentivá-la para a continuidade dos estudos e para não considerar comentários como este.

$\mathrm{Na}$ última aula da oficina foram reunidas as duas turmas de estudantes e, visando incentivá-los a dar continuidade aos estudos, foram apresentados casos de sucesso na área de Tecnologia da Informação, incluindo várias personalidades femininas que foram destaque para o desenvolvimento da tecnologia, como Ada Lovelace, Jean Sammet e Grace Hopper. Neste encontro também foi realizada a avaliação da aprendizagem, detalhada a seguir. 


\subsection{Avaliação da Oficina}

Para a avaliação da aprendizagem, a turma foi dividida em duplas formadas por um menino e uma menina, buscando também analisar a interação entre os mesmos. A referida avaliação consistia na montagem de um circuito a ser definido pelo grupo, criado a partir do que foi aprendido e de pesquisas realizadas na Internet. Após a finalização do projeto, os discentes apresentaram suas produções aos colegas. Durante esta atividade, observou-se que, em um primeiro momento, apenas uma dupla de fato trabalhou de forma colaborativa, as outras decidiram o que seria feito e escreveram os códigos individualmente. Após a intervenção das professoras, a interação se tornou efetiva e os alunos que terminaram primeiro passaram a ajudar os demais.

Ao final do encontro foi realizada a avaliação da oficina. Neste sentido, tanto os meninos quanto as meninas expressaram a vontade de dar continuidade aos estudos em nível superior e, alguns deles, explicitaram a intenção de atuar na área de computação. Entretanto, considera-se como um dos principais indicativos da avaliação positiva o fato dos participantes solicitarem uma nova edição desta oficina.

\section{Conclusão e Trabalhos Futuros}

Cerca de $47 \%$ dos discentes ingressantes finalizaram a oficina, deste percentual $60 \%$ eram estudantes do sexo feminino. Em uma conversa aberta, os estudantes puderam falar a respeito de suas percepções sobre o curso. As estudantes relataram ter aprendido a usar o computador e a internet para além de redes sociais, perceberam que podem ingressar em um curso superior, algo que até então as mesmas não pensavam em fazer. Consideramos que uma das principais contribuições está relacionada à autoconfiança que as meninas passaram ter, pois isso pode contribuir significativamente para a continuidade de seus estudos e para a ampliação do número de meninas que se dedica à área das Ciências Exatas.

Com a prática desta oficina foi possível observar algumas diferenças relacionadas ao gênero. No início das práticas alguns alunos demonstraram interesse em dar continuidade aos estudos em nível superior (realizando inscrição em processos seletivos e realizando curso fora da escola), já as alunas não tinham qualquer iniciativa neste sentido. E, através de conversas com as estudantes, foi possível perceber que o grande entrave em continuar os estudos, estava no âmbito familiar, pois elas não recebiam incentivo da família. Infelizmente, esta situação ainda é muito presente na sociedade e, segundo Moutinho (2014), "a família, a escola, a televisão, tudo que conforma a nossa sociedade, passa a ideia de que as mulheres não estão aptas para a matemática ou não têm compleição para as ciências que exigem raciocínio lógico mais forte" (MOUTINHO, 2014, p. 1).

Essa diferença é surpreendente, principalmente, quando comparada à realidade das professoras da oficina, também mulheres e estudantes do ensino superior em curso na área das Ciências Exatas. E, que durante sua infância/adolescência foram incentivadas, tanto por professores quanto pelos pais a estudar, a concluir um curso de graduação e a serem independentes. 
Observou-e, ainda, que a maioria das estudantes apresentava baixa autoestima, acreditava que não conseguiria concluir algo sozinha e não tinha interesse em realizar um curso de nível superior. Essa experiência foi bastante frustrante, principalmente, pela certeza de que esta situação ainda é comum no Brasil. Entretanto, encarou-se esta dificuldade como um desafio, e durante as oficinas isso foi trabalhado com as meninas em aula. Infelizmente, devido ao número de desistências de alunos a oficina está em processo de análise visando encaminhar novo processo de seleção de alunos junto à escola, contemplar um número maior de participantes, assim como sua manutenção na atividade.

\section{Referências}

MACIEL,C.; BIM, S. A. . Programa Meninas Digitais - Ações para divulgar a computação para meninas do ensino médio. In: Computer on the Beach, 2016, Itajaí - SC. Anais do Computer on the Beach 2016 e recurso eletrônico, 2016. p. 327-336.

MOUTINHO, S. Participação desigual. Instituto Ciência Hoje - Disponível em:<http://cienciahoje.uol.com.br/blogues/bussola/2014/03/participacao-desigual>. Acesso em: 19 de maio. 2018.

REVISTA NEUROEDUCAÇÃO. Sobre meninas e ciências exatas Disponível em: $<$ http://revistaneuroeducacao.com.br/sobre-meninas-e-ciencias-exatas/>. Acesso em 20 março. 2018.

SBC. Sociedade Brasileira de Computação. Educação superior em computação estatísticas. Disponível em:

$<$ http://sbc.org.br/documentos-da-sbc/summary/133-estatisticas/1167-educacao-supe rior-em-computacao-estatisticas-2016.

SOBREIRA, Josimeire de Lima. Estudantes de Engenharia da UTFPR: uma abordagem de gênero. 2006. 117p. Dissertação (Mestrado em Tecnologia) - PPGTE, UTFPR, Curitiba, 2006. 